\title{
In-vivo study using Raman Spectroscopy to estimate the effect of fairness creams on skin
}

\begin{abstract}
Serious scientific Research in the field of cosmetics has speared headed the growth of cosmetic industry, which adds undeniable credibility to the products. Many a time, a clinically simple, non-invasive dermatological technique is required to study the effect of the products in real time. Raman spectroscopy can be employed in his regard as it is a versatile technique which can be employed to study the nature and effects of these cosmetic products. In this short communication, we are reporting the study on the effect of fairness creams available in the market for the general Indian populace using Raman spectroscopy.
\end{abstract}

Volume 2 Issue 5 - 2018

\begin{abstract}
Amuthachelvi Daniel,' Wilfred Prasanna Savarimuthu, ${ }^{2}$ Gowripal Y, ${ }^{3}$ Prakasarao Aruna,' Singaravelu Ganesan'

'Department of Medical Physics, Anna University, India ${ }^{2}$ Department of Physics, Madras Christian College, India

${ }^{3}$ Department of Physics, Meenakshi College for Women, India
\end{abstract}

Correspondence: Amuthachelvi Daniel, Department of Medical Physics, Anna University, Chennai, India, Email amydany101।@gmail.com

Received: March 27, 2018 | Published: September 21, 2018

\section{Introduction}

Driven by medical, pharmaceutical, and cosmetic research, a large number of methods have been developed to obtain information about the presence and concentration of molecular compounds in the skin. Many of these methods are invasive, which require material to be removed from the skin and analyzed in vitro. ${ }^{1}$ They alter the system under investigation either by extraction of compounds from the skin or by physical disruption of cell layers. In a number of studies extraction techniques- are employed to determine concentration levels of free amino acids in the stratum corneum. ${ }^{1}$ Alternatively, Raman spectroscopy is a versatile technique which can be effectively employed to study biomolecules without any sample preparation. It can provide information on important molecules, natural moisturizing factors as well as exogenous molecules such as glycerol delivered from skin care products. ${ }^{2}$ Raman spectroscopy can directly measure the water content from the skin surface down to the upper epidermis with high depth resolution. ${ }^{3}$ Moreover, it produces a more absolute measurement value than other methods. The objective of this study is to measure the dermal changes caused by the commercially available fairness creams (in Indian market) in vivo using Raman spectroscopy and their effectiveness in reducing the melanin content in the skin.

\section{Materials and methods}

Study population includes twelve different subjects in the age group of 20-30 years and a written consent of the subjects. To evaluate the change, if present, before and after the application of five different creams, an attempt has been made using Raman spectroscopy. In this regard, the spectra were acquired at zero hour of the application of the cream and after one hour. Since Raman spectroscopic studies are noninvasive, the study can be repeated on the same skin area. Hence the effects of the molecules can be studied as a function of time.

\section{Experimental methods}

The spectroscopic study was carried out on a dedicated confocal Raman micro spectrometer. Raman spectra of the skin of forearm by using a sapphire ball lens fiber probe. A laser beam from a diode laser of fixed wavelength $784.12 \mathrm{~nm}$ was used. Light that is scattered by the tissue is collected by the same optical fiber connected to the spectrograph. The instrument was calibrated to the $520.7 \mathrm{~cm}^{-1}$ peak of silica. The integration time for every Raman spectrum was set to $20 \mathrm{sec}$ and every window was scanned twice to subtract cosmic showers. The spectra were acquired over a wave number region of 600 to $1800 \mathrm{~cm}^{-}$ ${ }^{1}$. This wave number region includes amide modes, protein and lipid Raman signature. The power at the sample was $26 \pm 0.5 \mathrm{~mW}$ for all the experiments performed. ${ }^{4}$

Every Raman instrument has a unique spectral responsiveness, to correct this; an intensity calibration factor was applied to every raw spectrum to obtain accurate and reproducible results. Then the spectra were baseline corrected using $5^{\text {th }}$ order polynomial, followed by spectral smoothening with Savityzy-Golay filter. All the data analyses mentioned above were performed using Labspec ${ }^{5}$ software provided by Horiba Jobin Yvon. The averaged Raman spectra of the control area and the different regions the creams are applied at zero hour and at the first hour are shown in (Figure 1A) (Figure 1B) respectively. Table 1 following table gives the major peaks that are present in the control area and the respective peak assignments.

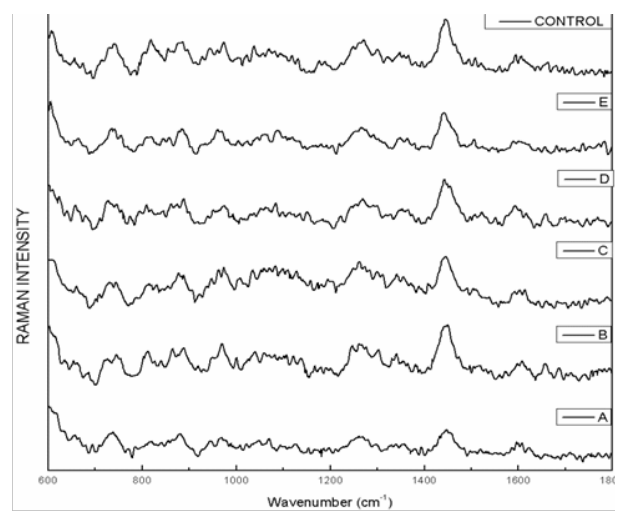

Figure IA Averaged spectral profile of the skin at zero hour after cream 


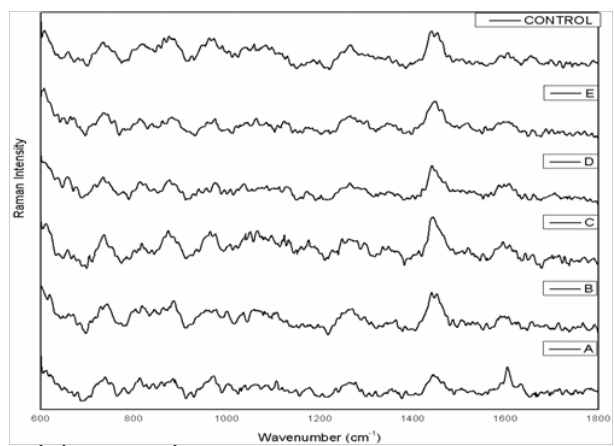

application and the control.

Figure IB Averaged spectral profile of the skin at first hour after cream application and the control.

Table I Normalized intensity of the peak at $1058 \mathrm{~cm}-$ I

\begin{tabular}{|c|c|}
\hline $\begin{array}{l}\text { Wave } \\
\text { number } \mathrm{cm}^{-1}\end{array}$ & Assignment \\
\hline 876 & C-C stretch, hydroxyproline \\
\hline 931 & $\mathrm{CH}_{3}$ rocking, collagen proline \\
\hline 951 & 4-hydroxy proline \\
\hline 963 & Apatite \\
\hline 1004 & Aromatic ring \\
\hline 1032 & Proline \\
\hline 1062 & Stretching (C-C) skeletal trans conformation lipid \\
\hline 1123 & Glycogen \\
\hline 1158 & Cartenoid \\
\hline 1176 & Tyrosine, phenyalanine \\
\hline 1200 & Hydroxyproline, tyrosine \\
\hline 1250 & Amide III \\
\hline 1265 & $\mathrm{C}-\mathrm{H}$ plane in deformation \\
\hline 1319 & $\mathrm{CH}_{3} \mathrm{CH}_{2}$ twisting \\
\hline 1343 & $\mathrm{CH}_{3} \mathrm{CH}_{2}$ wag \\
\hline 1385 & Deformational vibration $\left(\mathrm{CH}_{3}\right)$ symm \\
\hline 1445 & $\mathrm{CH}_{3} \mathrm{CH}_{2}$ deformation in collagen \\
\hline 1652 & Deformational vibration $(\mathrm{C}=0)$ amide I alpha-helix \\
\hline$|66|$ & Amide I \\
\hline
\end{tabular}

\section{Results}

\section{Spectral signature at zero hour}

The application of cream A resulted in the presence of peak at $1606 \mathrm{~cm}^{-1}$ and, a peak at $1105 \mathrm{~cm}^{-1}$. Further, broad peaks at 1380 and $1580 \mathrm{~cm}^{-1}$ were also observed in control. Cysteic acid, at $1045 \mathrm{~cm}^{-1}$, increased with bleaching, all the creams showed bleaching effect as there was increase in this peak intensity. There is a decreased intensity at 853 and $825 \mathrm{~cm}^{-1}$ peak on application of all the creams. The bands are diminished at $1004 \mathrm{~cm}^{-1}$ when creams D and $\mathrm{E}$ are applied. When cream B is applied, Raman shifts in $876 \mathrm{~cm}^{-1}$ to $890 \mathrm{~cm}^{-1}$ and there is a presence of band present at $1363 \mathrm{~cm}^{-1}$ and a vibration band at $1343 \mathrm{~cm}^{-1}$ is also seen when creams C, D and E were applied.

\section{Spectral signature at first hour}

After one hour, the averaged spectra of all five creams applied on the surface of the skin along with the control are shown in Figure 1B. A sharp peak at $1606 \mathrm{~cm}^{-1}$ was observed at zero hour of application of cream A and this peak was absent after an hour. Similarly the peak due to lipids at $1105 \mathrm{~cm}^{-1}$ was also absent. The peaks due to melanin at 1380 and $1580 \mathrm{~cm}^{-1}$ which were prominent in control, was found to be decreased where the creams A, B and C were applied even after an hour of application.

\section{Statistical analysis}

Principal component analysis was carried out for the two sets of data, viz., immediately after the application of the cream and after one hour of application. Both the sets yielded only two Principal Components (PC) that was statistically relevant. For these 2 PCs, ANOVA was carried out to test the significance of these extracted components. In both the cases the PC 2 yielded a better statistical significance than PC1. Supplementary Figures $1 \& 2$ show the score plots for both the data sets. After one hour of application of the cream, it can be inferred from the plot that the PC scores of the control and the cream applied regions are nearly the same. Spectral signature for different skin creams: The consistent peak at $1058 \mathrm{~cm}^{-1}$ is found to be shifted to $1045 \mathrm{~cm}^{-1}$ on application of the cream on the skin. Table 2 gives the prominent peaks and their peak assignments for the different creams and Table1 gives the normalized intensity of the peak at $1058 \mathrm{~cm}^{-1}$.

\section{Discussion}

\section{Spectral signature at zero hour}

The presence of peak at $1606 \mathrm{~cm}^{-1}$ which may be attributed to phenylalanine $e^{4}$ and peak at $1105 \mathrm{~cm}^{-1}$ which may be due to C-C stretch lipid. ${ }^{5}$ The broad peaks due to melanin at 1380 and $1580 \mathrm{~cm}^{-1}$ which is seen in control is decreased on application of cream $\mathrm{C}$ alone. ${ }^{6}$ The rest of the creams do not show any changes to the melanin content at the zero hour. Cysteic acid, at $1045 \mathrm{~cm}^{-1}$, increased with bleaching, all the creams showed bleaching effect as there was increase in this peak intensity. ${ }^{7}$ When there is a bleaching effect, the level of tyrosine decreases and is seen in the decreased intensity at 853 and $825 \mathrm{~cm}^{-}$ ${ }^{1}$ peaks on application of all the creams. ${ }^{7}$ The bands diminished at $1004 \mathrm{~cm}^{-1}$ are considered to be due to aromatic ring, when creams D and $\mathrm{E}$ applied may due to the bleaching effect of these creams. The Raman shift observed on applying cream B from $876 \mathrm{~cm}^{-1}$ (C-C stretch hydroxyproline) to $890 \mathrm{~cm}^{-1}$ (structural protein) and the band present at $1363 \mathrm{~cm}^{-1}$ are due to tryptophan. ${ }^{8,9}$ The vibration band at $1343 \mathrm{~cm}^{-1}$ is considered to be due to $\mathrm{CH}_{3} \mathrm{CH}_{2}$ wag, when creams $\mathrm{C}$, D and $\mathrm{E}$ were applied. ${ }^{10}$

\section{Spectral signature at first hour}

The intensity at $1045 \mathrm{~cm}^{-1}$ (Cysteic acid) was found to be still higher even after one hour of the application of the creams B, D and E. The level of tyrosine was found to be decreased when creams B, $\mathrm{D}$ and $\mathrm{E}$ were applied. The process of bleaching leads to lower levels of tyrosine.

\section{Spectral signature for different skin creams}


The cysteic acid in the creams is found as zwitterion cysteine tagged with Ag nanoparticles. ${ }^{11}$ Hence there is a consistent peak at $1058 \mathrm{~cm}^{-1}$. This peak is shifted to $1045 \mathrm{~cm}^{-1}$ on application of the cream on the skin which may be attributed to cystein oxidized to cysteic acid hence causing bleaching effect. From Table 2 which gives the prominent peaks and their peak assignments for the different creams. It is observed that, though all the creams exhibit bleaching effect when applied on the skin, Cream A does not exhibit the peak due to cysteine

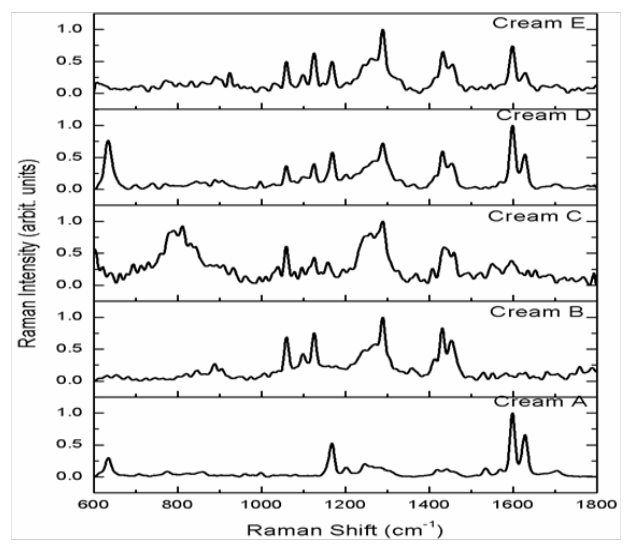

with nano particles peak at $1058 \mathrm{~cm}^{-1}$ as shown in Supplementary Table 1 (Figure 1C).

Figure IC Spectra of raw cream.

Table 2 Prominent peaks and their peak assignments for the different creams.

\begin{tabular}{|c|c|c|}
\hline $\begin{array}{l}\text { Wave } \\
\text { number } \\
\left(\mathrm{cm}^{-1}\right)\end{array}$ & Peak assignments & Creams \\
\hline 635 & Au nano particles & $A, D$ \\
\hline 1016 & tryptophan & B,C,D,E \\
\hline 1100 & $\mathrm{PO}_{2}$ stretch protein & $B, C, D, E$ \\
\hline 1129 & C-C stretch in lipid & $B, C, D, E$ \\
\hline II7| & $\gamma(C C)$ & $\mathrm{A}, \mathrm{C}, \mathrm{D}, \mathrm{E}$ \\
\hline 1290 & amide III C-N & $B, C, D, E$ \\
\hline$|43|$ & $\mathrm{CH}_{2}$ bending and wagging & $B, C, D, E$ \\
\hline 1456 & $\mathrm{CH}_{3}$ bending in elastin & $B, C, D, E$ \\
\hline 1600 & Au nano particles & $A, C, D, E$ \\
\hline 1058 & zwitterions cysteine with $\mathrm{Ag}$ nanoparticles & $A, B, C, D, E$ \\
\hline
\end{tabular}

\section{Conclusion}

In conclusion, this pilot study reveals that every cream lightens the skin by bleaching it. This bleaching effect of the skin can be attributed to the oxidation of cystein to cysteic acid. This effect is a short term effect. It was observed that, as the time progresses from the time of application, the skin does not exhibit the bleaching effect as the PC scores plot shows. Furthermore, the study has to be carried for the longer duration of continued application.

\section{Acknowledgements}

None.

\section{Conflict of interest}

Author declares that there is no conflict of interest.

\section{References}

1. Caspers PJ, Lucassen GW, Carter EA, et al. In Vivo Confocal Raman Microspectroscopy of the Skin: Noninvasive Determination of Molecular Concentration Profiles. J Invest Dermatol. 2001;116(3):434-442.

2. Nakagawa N, Matsumoto M, Sakai S. In vivo measurement of the water content in the dermis by confocal Raman spectroscopy. Confocal Raman spectroscopy. Skin Res Technol. 2010;16(2):137-141.

3. TeixeiraI AP, João LR, Leandro JRI, et al. Confocal Raman spectroscopy: determination of natural moisturizing factor profile related to skin hydration. Rev Bras Eng Bioméd. 2014;30(1).

4. Huleihel M, Shufan E, Zeiri L, et al. Detection of Vero Cells Infected with Herpes Simplex Types 1 and 2 and Varicella Zoster Viruses Using Raman Spectroscopy and Advanced Statistical Methods. PLoS One. 2016;14;11(4):e0153599.

5. Faiman R. An Analysis of Band Profiles in the Raman Spectra of an Aqueous Dispersion of Sphingomyelin. Chemistry and Physics of Lipids. 1979;23(1):77-84.

6. Huang Z, Lui H, Chen XK, et al. Raman spectroscopy of in vivo cutaneous melanin. J Biomed Opt. 2004;9(6):1198-1205.

7. Barel AO. Handbook of Cosmetic Science and Technology. 4th ed. In: André O Barel, Marc Paye, Howard I, editors. Maibach: CRC Press; 2014.

8. Nguyen TT, Gobinet C, Feru J, et al. Characterization of Type I and IV Collagens by Raman Microspectroscopy: Identification of Spectral Markers of the Dermo-Epidermal Junction. Spectroscopy: An International Journal. 2012;27(5-6):421-427.

9. Evans CH. Applications of Infrared, Raman, and Resonance Raman Spectroscopy in Biochemistry. In: Frank SP, editor. Trends in Biochemical Sciences. New York and London: Plenum Press. 1983;9(6):289.

10. Frank CJ, McCreery RL, Redd DC. Raman Spectroscopy of Normal and Diseased Human Breast Tissues. Anal Chem. 1995;67(5):777-783.

11. Thibault B, Yockell-Lelievre H, Bouhelier A, et al. Sorting of Enhanced Reference Raman Spectra of a Single Amino Acid Molecule. J Phys Chem C. 2014;118(31):17975-17982. 